\title{
Effect of L-arginine treatment on motility, hyperactivity, acrosome reaction of ejaculated ram spermatozoa
}

\author{
K.H. El-Shahat ${ }^{1,4}$, M.I. Taysser ${ }^{1}$, M.R. Badr ${ }^{2}$, K. Zaki ${ }^{3}$ \\ ${ }^{1}$ Department of Theriogenology, Faculty of Veterinary Medicine, Cairo University, Giza, Egypt. \\ ${ }^{2}$ Department of Animal Reproduction and Artificial Insemination, Reproduction Research Institute, Giza, Egypt. \\ ${ }^{3}$ El Shiekh Zaied Veterinary Clinic, Giza, Egypt.
}

\begin{abstract}
The aim of this study was to evaluate the effect of in vitro treatment of ejaculated ram spermatozoa with different concentrations of L-arginine at various incubation times on motility, hyperactivity (HA) and acrosome reaction. Freshly ejaculated spermatozoa collected from three rams were pooled and subjected to the swim up technique in modified sperm Tyrode's albumin lactate pyruvate (S-TALP) medium supplemented with different concentrations of Larginine $(0.01,0.02,0.03,0.04$ and $0.05 \mathrm{mM})$ at 30 , 60,90 and $120 \mathrm{~min}$ of incubation. Following sperm incubation, the following parameters were examined: motility, hyperactivity (HA) and acrosome reaction (AR). The results showed that irrespective of the concentration, incubation of ram spermatozoa with Larginine for $30 \mathrm{~min}$ did not significantly affect the motility. However, increase the time of incubation for more than 30 min significantly decreased $(P<0.05)$ the motility of the spermatozoa as compared to the control. The lowest motility was recorded when spermatozoa were incubated with $0.05 \mathrm{mM} \mathrm{L}$-arginine for $120 \mathrm{~min}$. Treatment of ram spermatozoa with $0.05 \mathrm{mM} \mathrm{L}$ arginine resulted in a significant $(\mathrm{P}<0.05)$ increase in $\mathrm{HA} \%$ immediately after dilution compared to the control. A significant $(P<0.05)$ increase in total $A R \%$ was concomitant to the increase in the concentration of L-arginine with highest $\mathrm{AR}$ achieved at $0.04 \mathrm{mM}$ and 90 $\mathrm{min}$ incubation. However, increasing the time of incubation to 120 min significantly decreased $(\mathrm{P}<0.05)$ the percentage of spermatozoa with total AR compared to the other incubation times at $0.02,0.04$, and $0.05 \mathrm{mM}$ L-arginine. In conclusion, under our experimental conditions treatment of ejaculated ram spermatozoa with $0.04 \mathrm{mM}$ of L-arginine for $90 \mathrm{~min}$ was considered the best concentration of L-arginine to be used for in vitro induction of acrosome reaction.
\end{abstract}

Keywords: acrosome reaction, hyperactivation, L-arginine, ram sperm.

capacitation,

\section{Introduction}

L-arginine is an amino acid that acts as a substrate for the Nitric Oxide Synthase Enzyme (NOS) producing nitric oxide (NO; O'Flaherty et al., 2004). Larginine takes part in sperm formation and is found to be a basic component of the nucleoprotein of spermatozoa of various species (Adnan, 1970). There is correlation between arginine deficiency and loss of spermatogenesis and decrease in the motility of the sperm cell (Jungling and Bunge, 1976; Polakoski et al., 1976). Arginine plays a vital role in the maintenance of sperm motility and their metabolic activity inside the reproductive tract or throughout storage under in vitro conditions (Mann and Lutwak-Mann, 1981). Also, arginine prevents bilayer phospholipids membrane peroxidation under various peroxidation situations through production of nitric oxide (NO) mechanism which protects structural and functional integrity of spermatozoa (Govil et al., 1992; Srivastava et al., 2006). L-arginine plays a key role in modulating the host's defense and cellular immunity. Administration of L-arginine to oligospermic and asthenospermic patients results in an improvement in both the sperm count and motility without any side effects (Scibona et al., 1994; Aydin et al.; 1995). L-arginine plays an important role in stimulating sperm motility in humans, rabbits, and goats under in vitro conditions (Aydin et al., 1995; Patel et al., 1998; Srivastava et al., 2006). It has been confirmed that L-arginine enhances the rate of glycolysis, resulting in higher rates of adenosine triphosphate and lactate generation in spermatozoa. The influence of arginine in reversing impairment caused by glycolytic inhibitors (potential contraceptives) has also been studied (Patel et al., 1998, 1999). NO promotes mouse sperm capacitation and acrosome reaction (Griveau et al., 1995). Several researches indicated that NO generated by human spermatozoa regulates sperm capacitation and associated protein tyrosine phosphorylation that mediated through a cAMP/PKAdependent pathway (De Lamirande and Gagnon, 1998; Visconti and Kopf, 1998; Thundathil et al., 2003). NO stimulates hyperactivationmotility (Herrero and Gagnon 2001). Sperm hyper activation motility is promoted by exogenous addition of $\mathrm{NO}$ which may increase phosphorylation of flagella proteins (Thundathil et al., 2003; Harrison, 2004). Hyperactivation is crucial for sperm to penetrate the zona pellucid viscose environment that surrounds the oocyte (Gagnon and de Lamirande, 2006). Therefore, L-arginine as a resource of NO may induce capacitation and acrosome reaction through the NO signal pathway. However, little is known about the effect of L-arginine and NO on ram spermatozoa (Hassanpour et al., 2007, 2010). Therefore, the present study aimed to investigate the effect of different concentrations and incubation times of Larginine on the motility, hyperactivity, and acrosome reaction of ram spermatozoa.

${ }^{4}$ Corresponding author: attiakh@yahoo.com 


\section{Materials and Methods}

\section{Animal management and semen collection}

The study was performed on three mature Barki rams (3-5 years old) in a farm at the Animal Reproduction Research Institute (Egypt) from December to March, 2015. The rams were kept as a single flock under uniform conditions. The average body weight of Barki rams was $45 \mathrm{~kg}$ and body condition scores (BCs) were 3.0-4.0. All rams were fed Egyptian clover (Trifolume alexandrium), besides the green maize (Darawa) and wheat straw as a source of roughage.

\section{Semen processing and sperm capacitation}

Semen were collected from Barki rams $(n=30$ ejaculates) using an artificial vagina twice a week. In each ejaculate, volume, concentration, sperm motility and morphology were assessed within $30 \mathrm{~min}$ after semen collection and placed in a water bath at $\left(37^{\circ} \mathrm{C}\right)$ Ejaculates that contained a volume of $0.5-2 \mathrm{ml}$; minimum semen concentration of $3 \times 10^{9}$ spermatozoa $/ \mathrm{ml}$; total motility higher than $80 \%$; $<10 \%$ abnormal sperm were pooled together to avoid individual variability of rams and then were used for the experiment according to the method described by Chemineau et al. (1991). Split fractions $(0.1 \mathrm{ml})$ of the pooled semen were layered under $1 \mathrm{ml}$ of sperm Tyrode's albumin lactate pyruvate (S-TALP) medium according to the method described by Younis et al. (1991) supplemented with different concentrations of Larginine $(0.01,0.02,0.03,0.04$ and $0.05 \mathrm{mM})$. Semen diluted in S-TALP medium without treatment was used as a control. This technique (swim up technique) was performed in $15 \mathrm{ml}$ centrifuge tubes, held at a $45^{\circ}$ angle and incubated in an atmosphere of $5 \% \mathrm{CO}_{2}$ incubator at $39^{\circ} \mathrm{C}$. Individual motility percentage (IM\%), hyperactivity percentage $(\mathrm{HA} \%)$ and acrosome status were recorded at $0,30,60,90$ and $120 \mathrm{~min}$ postincubation.

\section{Evaluation of sperm motility}

Percentage of progressive forward motility was subjectively estimated in a small drop $(200 \mu \mathrm{l})$ of the sperm suspension from the most supernatant of swim up and covered by a cover slip, and examined under phase contrast microscope (40X) equipped with a heated plate $\left(37^{\circ} \mathrm{C}\right)$. Only progressive forward motility was considered among different treatments and control. At least 100 spermatozoa in five different fields were counted.

\section{Evaluation of sperm hyperactivity}

Percentage of hyperactivated motility (HA\%) was determined by recording the percentage of sperm cells with flagellar beating vigor and circular movement (Kawakami et al., 1999). Hyperactivated motility percentage was calculated as a percentage from the percentage of IM\% and expressed by "pluses" where $(+)$ means $\mathrm{HA} \%<20 \%$, + means $\mathrm{HA} \% 20-40 \%$, ++ means HA $\% 40-60 \%$, +++ means HA $\% 60-80 \%$ and ++++ means HA $\%>80 \%$ (Darwish, 2004).

\section{Evaluation of sperm acrosome status}

Percentages of incomplete and complete acrosome reacted spermatozoa were determined by silver nitrate staining technique according to El-Amrawi and Nemetallah (1991). The sperm suspensions were spread over microscope glass slides and left at room temperature to dry. The slides were fixed in $70 \%$ ethyl alcohol for 2 min then in $95 \%$ ethyl alcohol for another $2 \mathrm{~min}$. The samples were then stained with a silver nitrate $(1 \%)$ solution for $2 \mathrm{~h}$ in an incubator at $65^{\circ} \mathrm{C}$, in complete humidity. After the color of the samples turned into gold, the reaction was stopped and the slides were rinsed several times with distilled water and dried at room temperature. The dyed preparations were analyzed for acrosome reaction using the Olympus BX50 light microscope with a 100-fold magnification under oil immersion lens. The percentage of acrosome reacted sperm was counted in at least 100 sperm cells per slide. The spermatozoa were classified into three groups: (1) spermatozoa with intact plasma and outer acrosome; (2) spermatozoa with incomplete acrosome reaction (AR) showing fenestrations, vesiculation and loosening between plasma membrane and outer acrosome membrane; and (3) spermatozoa with complete AR showing complete loss of the outer acrosome membrane leaving a cup-shaped appearance. Incomplete plus complete acrosome percentages were considered collectively as total acrosome reaction.

\section{Statistical analysis}

Data were expressed as mean \pm SEM that is obtained from 10 replicates for motility, hyperactivity and acrosome reaction and were analyzed using the Costat computer program; version 3.03, 1986, Cottort Software. Data from 10 replicates were subjected to analysis of variance (two way ANOVA) to clarify the effect of L- arginine concentrations and incubation times. P-values below $0.05 \%$ were considered statistically significant.

\section{Results}

Effect of different concentrations of L-arginine on ram sperm motility

No significant differences were observed in total motility between control and L-arginine treated groups at $0 \mathrm{~min}$ incubation and the values ranged from 82.50 and $83.5 \%$. Treatment of ram spermatozoa with different concentrations of L-arginine $(0.01,0.02,0.04$, and $0.05 \mathrm{mM}$ ) for 90 or $120 \mathrm{~min}$ significantly decreased the motility when compared to the control. At $120 \mathrm{~min}$ incubation no significant differences were observed in the percentage of total motility among different treatments (Table 1). 
Table1. Effect of different L-arginine concentrations $(\mathrm{mM})$ and incubation times on motility of ram spermatozoa (Mean $\pm \mathrm{SE})$.

\begin{tabular}{lccccc}
\hline \multirow{2}{*}{ L-arginine $(\mathrm{mM})$} & \multicolumn{4}{c}{ Incubation Time } \\
\cline { 2 - 6 } & 0 & $30 \mathrm{~min}$ & $60 \mathrm{~min}$ & $90 \min$ & $120 \mathrm{~min}$ \\
\hline Control & $82.50 \pm 0.83^{\mathrm{Aa}}$ & $77.50 \pm 0.83^{\mathrm{Ab}}$ & $76.50 \pm 1.3^{\mathrm{Ab}}$ & $75.00 \pm 1.29^{\mathrm{Ab}}$ & $61.50 \pm 2.47^{\mathrm{Ac}}$ \\
0.01 & $82.50 \pm 0.83^{\mathrm{Aa}}$ & $74.50 \pm 1.38^{\mathrm{Ab}}$ & $65.00 \pm 1.29^{\mathrm{Bc}}$ & $46.50 \pm 1.30^{\mathrm{Cd}}$ & $27.00 \pm 3.10^{\mathrm{Be}}$ \\
0.02 & $83.00 \pm 0.81^{\mathrm{Aa}}$ & $75.50 \pm 1.38^{\mathrm{Ab}}$ & $70.50 \pm 2.29^{\mathrm{ABb}}$ & $56.00 \pm 3.23^{\mathrm{Bc}}$ & $26.50 \pm 3.25^{\mathrm{Bd}}$ \\
0.04 & $82.50 \pm 0.76^{\mathrm{Aa}}$ & $75.00 \pm 1.49^{\mathrm{Aa}}$ & $65.50 \pm 2.62^{\mathrm{Bb}}$ & $55.00 \pm 2.68^{\mathrm{Bc}}$ & $30.50 \pm 4.31^{\mathrm{Bd}}$ \\
0.05 & $83.50 \pm 0.76^{\mathrm{Aa}}$ & $75.00 \pm 1.49^{\mathrm{Ab}}$ & $71.50 \pm 1.97^{\mathrm{ABb}}$ & $55.50 \pm 2.03^{\mathrm{Bc}}$ & $34.00 \pm 1.45^{\mathrm{Bd}}$ \\
\hline
\end{tabular}

Means with different alphabetical superscripts in the same column ${ }^{\mathrm{A}, \mathrm{B}, \mathrm{C}}$ and different rows ${ }^{\mathrm{a}, \mathrm{b}, \mathrm{c}}$ are significant $\mathrm{P}<0.05$.

Effect of different concentrations of L-arginine on ram sperm hyperactivity (HA \%)

It was clear that the addition of $0.05 \mathrm{mM} \mathrm{L-}$ arginine to semen samples resulted in a significant increase $(\mathrm{P}<0.05)$ in $\mathrm{HA} \%(3.80 \%)$ at $0 \mathrm{~h}$ incubation when compared to the control $(0.0 \%)$. The highest percentages of hyperactivated motility were noticed in spermatozoa that were treated with 0.04 and $0.05 \mathrm{mM}$ L-arginine for 30 and $60 \mathrm{~min}$ (Table 2).

Table2. Effect of different L-arginine concentrations $(\mathrm{mM})$ and incubation times on hyperactivity of ram spermatozoa (Mean $\pm \mathrm{SE}$ ).

\begin{tabular}{lccccc}
\hline \multirow{2}{*}{ L-arginine $(\mathrm{mM})$} & \multicolumn{4}{c}{ Incubation Time } \\
\cline { 2 - 6 } & 0 & $30 \mathrm{~min}$ & $60 \mathrm{~min}$ & $90 \mathrm{~min}$ & $120 \mathrm{~min}$ \\
\hline Control & $0.00 \pm 0.00^{\mathrm{Cc}}$ & $0.00 \pm 0.00^{\mathrm{Bc}}$ & $0.00 \pm 0.00^{\mathrm{Bc}}$ & $0.60 \pm 0.16^{\mathrm{Bb}}$ & $1.40 \pm 0.26^{\mathrm{Ba}}$ \\
0.01 & $1.80 \pm 0.32^{\mathrm{Bb}}$ & $4.40 \pm 0.33^{\mathrm{Aa}}$ & $4.60 \pm 0.26^{\mathrm{Aa}}$ & $3.80 \pm 0.24^{\mathrm{Aa}}$ & $2.40 \pm 0.16^{\mathrm{Ab}}$ \\
0.02 & $2.40 \pm 0.39^{\mathrm{Bb}}$ & $4.40 \pm 0.33^{\mathrm{Aa}}$ & $4.00 \pm 0.29^{\mathrm{Aa}}$ & $4.20 \pm 0.38^{\mathrm{Aa}}$ & $2.40 \pm 0.16^{\mathrm{Ab}}$ \\
0.04 & $2.60 \pm 0.33^{\mathrm{Bc}}$ & $5.60 \pm 0.54^{\mathrm{Aa}}$ & $5.00 \pm 0.29^{\mathrm{Aa}}$ & $4.00 \pm 0.20^{\mathrm{Ab}}$ & $2.60 \pm 0.26^{\mathrm{Ac}}$ \\
0.05 & $3.80 \pm 0.61^{\mathrm{Abc}}$ & $5.60 \pm 0.54^{\mathrm{Aa}}$ & $5.00 \pm 0.36^{\mathrm{Aab}}$ & $4.20 \pm 0.43^{\mathrm{Aab}}$ & $2.60 \pm 0.26^{\mathrm{Ac}}$ \\
\hline
\end{tabular}

Means with different alphabetical superscripts in the same column ${ }^{\mathrm{A}, \mathrm{B}, \mathrm{C}}$ and different rows ${ }^{\mathrm{a}, \mathrm{b}, \mathrm{c}}$ are significant $\mathrm{P}<0.05$.

Effect of different concentrations of L-arginine on the percentage of spermatozoa with incomplete acrosome reaction $(I A R \%)$

As shown in Table 3, adding different concentrations of L-arginine significantly $(\mathrm{P}<0.05)$ increased the percentages of spermatozoa with incomplete acrosome reaction (IAR) and were significantly higher $(\mathrm{P}<0.05)$ in $\mathrm{L}$-arginine treated groups when compared to control irrespective of the incubation time. The highest IAR\% was detected in sperm samples treated with $0.04 \mathrm{mM} \mathrm{L}$-arginine for $90 \mathrm{~min}$ $(44.00 \pm 3.10)$. The percentages of spermatozoa with IAR were increased by incubation time and reached the maximum at $120 \mathrm{~min}$ incubation $(8.80 \pm 1.72)$. However, in the treated groups the IAR\% significantly decreased at $120 \mathrm{~min}$ incubation when compared to those incubated for 30,60 , and $90 \mathrm{~min}$.

Table3. Effect of different L-arginine concentrations $(\mathrm{mM})$ and incubation times on incomplete acrosome reaction of ram spermatozoa (Mean $\pm \mathrm{SE})$.

\begin{tabular}{|c|c|c|c|c|c|}
\hline \multirow{2}{*}{ L-arginine $(\mathrm{mM})$} & \multicolumn{5}{|c|}{ Incubation time } \\
\hline & 0 & $30 \mathrm{~min}$ & $60 \mathrm{~min}$ & $90 \mathrm{~min}$ & $120 \mathrm{~min}$ \\
\hline Control & $0.00 \pm 0.00^{\mathrm{Bb}}$ & $0.00 \pm 0.00^{\mathrm{Db}}$ & $7.00 \pm 1.02^{\mathrm{Ca}}$ & $8.30 \pm 0.87^{\mathrm{Ca}}$ & $8.80 \pm 1.72^{\mathrm{Ba}}$ \\
\hline 0.01 & $4.50 \pm 0.80^{\mathrm{Ac}}$ & $19.30 \pm 1.55^{\mathrm{Cb}}$ & $25.3 \pm 1.45^{\mathrm{Ba}}$ & $24.90 \pm 1.28^{\mathrm{aB}}$ & $16.60 \pm 1.55^{\mathrm{Ab}}$ \\
\hline 0.02 & $5.90 \pm 1.09^{\mathrm{Ad}}$ & $26.40 \pm 2.16^{\mathrm{B} \mathrm{b}}$ & $27.20 \pm 1.98^{\mathrm{Bb}}$ & $39.20 \pm 2.65^{\mathrm{Aa}}$ & $12.40 \pm 1.04^{\mathrm{Bc}}$ \\
\hline 0.04 & $7.4 \pm 1.33^{\mathrm{Ad}}$ & $33.10 \pm 2.06^{\mathrm{Ab}}$ & $38.60 \pm 2.84^{\mathrm{Aa}}$ & $44.00 \pm 3.10^{\mathrm{Aa}}$ & $18.80 \pm .087^{\mathrm{Ac}}$ \\
\hline 0.05 & $7.60 \pm 1.46^{\mathrm{Ad}}$ & $24.10 \pm 1.77^{\mathrm{BCb}}$ & $25.30 \pm 1.34^{\mathrm{Bb}}$ & $40.40 \pm 2.27^{\mathrm{Aa}}$ & $17.50 \pm 1.00^{\mathrm{Ac}}$ \\
\hline
\end{tabular}

Means with different alphabetical superscripts in the same column ${ }^{\mathrm{A}, \mathrm{B}, \mathrm{C}}$ and different rows $\mathrm{s}^{\mathrm{a}, \mathrm{b}, \mathrm{c}}$ are significant $\mathrm{P}<0.05$.

Effect of different concentrations of L-arginine on spermatozoa showing complete acrosome reaction percentage $(C A R \%)$

Treatment of ram spermatozoa with $0.04 \mathrm{mM}$ L-arginine significantly increased $(\mathrm{P}<0.05)$ the percentage of spermatozoa with complete acrosome reaction (CAR) when compared to the other concentrations at different incubation times (Table 4).
Effect of different concentrations of L-arginine on total acrosome reaction percentage (TAR \%)

The highest percentage of spermatozoa with AR was noticed when sperm samples were treated with 0.04 $\mathrm{mM}$ for $90 \mathrm{~min}(93.10 \pm 3.35)$. Moreover, within each concentration of L-arginine treatment, AR\% gradually increased by incubation with the highest values seen at 90 min, then these values significantly decreased at $120 \mathrm{~min}$ compared to other incubation times (Table 5). 
Table 4. Effect of different L-arginine concentrations ( $\mathrm{mM})$ and incubation times on complete acrosome reaction of ram spermatozoa (Mean $\pm \mathrm{SE}$ ).

\begin{tabular}{|c|c|c|c|c|c|}
\hline \multirow{2}{*}{ L-arginine $(\mathrm{mM})$} & \multicolumn{5}{|c|}{ Incubation time } \\
\hline & 0 & $30 \mathrm{~min}$ & $60 \mathrm{~min}$ & $90 \mathrm{~min}$ & $120 \mathrm{~min}$ \\
\hline Control & $0.00 \pm 0.00^{\mathrm{Cb}}$ & $0.00 \pm 0.00^{\mathrm{Eb}}$ & $0.00 \pm 0.00^{\mathrm{Db}}$ & $3.80 \pm 0.96^{\mathrm{Ea}}$ & $4.10 \pm 0.82^{\mathrm{Da}}$ \\
\hline 0.01 & $5.20 \pm 1.87^{\mathrm{Bb}}$ & $8.70 \pm 1.66^{\mathrm{Db}}$ & $19.20 \pm 1.82^{\mathrm{Ca}}$ & $10.80 \pm 1.25^{\mathrm{Db}}$ & $16.50 \pm 1.77^{\mathrm{Ca}}$ \\
\hline 0.02 & $8.50 \pm 1.24^{\mathrm{Bc}}$ & $19.00 \pm 1.78^{\mathrm{Cb}}$ & $26.30 \pm 1.24^{\mathrm{Ba}}$ & $22.60 \pm 1.92^{\mathrm{Cab}}$ & $18.40 \pm 2.23^{\mathrm{Cb}}$ \\
\hline 0.04 & $15.90 \pm 1.25^{\mathrm{Ab}}$ & $37.60 \pm 1.78^{\mathrm{Aa}}$ & $42.60 \pm 2.28^{\mathrm{Aa}}$ & $49.10 \pm 3.05^{\mathrm{Aa}}$ & $46.00 \pm 2.53^{\mathrm{Aa}}$ \\
\hline 0.05 & $5.20 \pm 1.82^{\mathrm{Bd}}$ & $26.80 \pm 1.92^{\mathrm{Bc}}$ & $30.20 \pm 2.68^{\mathrm{Bbc}}$ & $40.00 \pm 1.86^{\mathrm{Ba}}$ & $34.20 \pm 1.85^{\mathrm{Bb}}$ \\
\hline
\end{tabular}

Means with different alphabetical superscripts in the same column ${ }^{\mathrm{A}, \mathrm{B}, \mathrm{C}}$ and different rows $\mathrm{s}^{\mathrm{a}, \mathrm{b}, \mathrm{c}}$ are significant $\mathrm{P}<0.05$.

Table 5. Effect of different L-arginine concentrations ( $\mathrm{mM})$ and incubation times on total acrosome reaction of ram spermatozoa (Mean $\pm \mathrm{SE}$ ).

\begin{tabular}{|c|c|c|c|c|c|}
\hline \multirow{2}{*}{$\begin{array}{l}\text { L- arginine } \\
(\mathrm{mM})\end{array}$} & \multicolumn{5}{|c|}{ Incubation time } \\
\hline & 0 & $30 \mathrm{~min}$ & $60 \mathrm{~min}$. & $90 \mathrm{~min}$ & 120 min. \\
\hline Control & $00.00 \pm 0.00^{\mathrm{Cc}}$ & $0.00 \pm 0.00^{\mathrm{Dc}}$ & $7.00 \pm 1.02^{\mathrm{Db}}$ & $12.1 \pm 1.56^{\mathrm{Ea}}$ & $12.90 \pm 1.90^{\mathrm{Da}}$ \\
\hline 0.01 & $9.70 \pm 2.12^{\mathrm{ABc}}$ & $28.00 \pm 2.93^{\mathrm{Cb}}$ & $44.50 \pm 2.81^{\mathrm{Ca}}$ & $35.70 \pm 1.41^{\mathrm{Db}}$ & $33.10 \pm 3.17^{\mathrm{Cb}}$ \\
\hline 0.02 & $14.40 \pm 1.67^{\mathrm{Ad}}$ & $45.40 \pm 3.50^{\mathrm{Bb}}$ & $53.50 \pm 2.55^{\mathrm{Bab}}$ & $61.80 \pm 3.7^{\mathrm{Ca}}$ & $30.80 \pm 2.78^{\mathrm{Cc}}$ \\
\hline 0.04 & $23.30 \pm 1.79^{\mathrm{Ad}}$ & $70.70 \pm 3.83^{\mathrm{Ac}}$ & $81.20 \pm 4.39^{\mathrm{Ab}}$ & $93.10 \pm 3.35^{\mathrm{Aa}}$ & $64.80 \pm 3.02^{\mathrm{Ac}}$ \\
\hline 0.05 & $12.80 \pm 2.46^{\mathrm{Bc}}$ & $50.90 \pm 3.41^{\mathrm{Bb}}$ & $55.50 \pm 3.55^{\mathrm{Bb}}$ & $80.40 \pm 1.50^{\mathrm{Ba}}$ & $51.70 \pm 2.16^{\mathrm{Bb}}$ \\
\hline
\end{tabular}

Means with different alphabetical superscripts in the same column ${ }^{\mathrm{A}, \mathrm{B}, \mathrm{C}, \mathrm{D}}$ and different rows ${ }^{\mathrm{a}, \mathrm{b}, \mathrm{c}, \mathrm{d}}$ are significant $\mathrm{P}<0.05$.

\section{Discussion}

The present results show that incubation of ejaculated ram spermatozoa with L-arginine at various concentrations $(0.01,0.02,0.04$, and $0.05 \mathrm{mM})$ for periods longer than $60 \mathrm{~min}$ namely 90 or $120 \mathrm{~min}$ significantly decreased total motility compared to the control group. In contrast, Hassanpour et al. (2007 ) reported that the effects of L-arginine on ejaculated sperm motility are dose-dependent and the low concentrations of L-arginine $(0.1$ and $1 \mathrm{mM})$ affect sperm motility, whilst high concentrations of Larginine $(10 \mathrm{mM})$ significantly decrease sperm motility to $10 \%$. However, Hassanpour et al. (2010) recorded that low concentrations of L-arginine $(0.001,0.01$ and $0.1 \mathrm{mM}$ ) after 45 or $90 \mathrm{~min}$ of incubation had little effect on ram sperm motion parameters; whereas high concentration of L-arginine $(1 \mathrm{mM})$ significantly decreased specific motion parameters (straightness, curvilinear velocity, and straight-line velocity). Similarly, Darwish (2004) and Marie (2005) observed no significant effect on motility when buffalo semen was supplemented with low concentrations of Larginine $(<0.5 \mathrm{mg} / \mathrm{ml})$ for $30 \mathrm{~min}$ incubation. However, when higher concentrations or longer incubation time was used, a significant $(\mathrm{P}<0.01)$ decrease in motility was achieved. Furthermore, Rodriguez et al. (2005) reported that low concentrations (ranging from 0.05 to $200 \mu \mathrm{m}$ ) of Sodium nitroprusside (SNP; a NO. donor) fail to affect either motility or viability of bull spermatozoa, but concentrations higher than $400 \mu \mathrm{m}$ reduced motility in a dose-dependent manner. In contrast, Al-Ebady et al. (2012) recorded that the addition of 0.005 or $0.006 \mathrm{M}$ of arginine to semen diluents containing poor motile bull sperm improved sperm motility and decreased death, abnormality and defect in the acrosome of sperm, especially during the months of December and January. The difference in methodology and species used has probably resulted in the disparate results obtained. It is tempting to speculate in our study that high concentration of L-arginine $(0.04$ and $0.05 \mathrm{mM}$ ), probably by excessive generation of $\mathrm{NO}$, can cause sperm toxicity as well as reduce sperm motility by contributing to the formation of peroxynitrite, a highly toxic anion of peroxidation Levonen. 2001). Furthermore, Rodriguez et al. (2005) proposed that high concentrations of NO can cause sperm cytotoxicity, possibly due to the inhibitory effect of nitric oxide when binding to the heme group contained in enzymes of cellular respiration. The nitration of those proteins, for example cytochrome oxidase, results in a decrease in the production of ATP required as an energy source by spermatozoa. Additionally, $\mathrm{NO}$ could interact with the $\mathrm{O}_{2}{ }^{-}$to form the peroxynitrite anion. This molecule is very reactive and could act on cytosolic or membrane compounds such as lipids or proteins with thiol groups, affecting the integrity of the sperm membrane. Although the incubation of ram spermatozoa with different concentrations of L-arginine for a long time (90-120 min) decreased the sperm motility in our study, it increased hyperactivity at a concentration of 0.04 and $0.05 \mathrm{mM}$. This may be attributed to the change in the motility from progressive forward motility to circular, with flagellar beating vigor as indication of hyperactivity (Darwish, 2004; Marie, 2005). Sperm hyper activation motility is promoted by exogenous addition of NO which may increase phosphorylation of flagella proteins (Thundathilet al., 2003; Harrison, 2004). Hyper activation is crucial for sperm to penetrate the zona pellucid viscose environment that surrounds the oocyte (Gagnon and De Lamirande, 2006). However, Ratnasooriya and Dharmasiri (2001) demonstrated that L-arginine caused a dose-dependent impairment of hyperactivated motility in vitro, which can obviously inhibit fertilizing potential of sperm. In the present study, relatively high concentrations of Larginine $(0.04 \mathrm{mM})$ were required to induce acrosome reaction in ram spermatozoa. Regarding incubation times, a significant $(\mathrm{P}<0.05)$ increase in total $A R \%$ 
was also noticed after incubation for $90 \mathrm{~min}$. In agreement with our data, Darwish (2004) and Marie (2005) recorded that relatively higher concentrations of L-arginine were required to induce acrosome reaction in buffalo spermatozoa. Furthermore, O'Flaherty et al. (2004) successfully induced capacitation and AR in bovine spermatozoa using L-arginine. In addition, the effect of L-arginine on bovine sperm capacitation process and AR was mediated by NOS, as when the spermatozoa were incubated with L-arginine in the presence of NOS inhibitors, results indicate a significant inhibition of capacitation. NO promotes mouse sperm capacitation and acrosome reaction (Griveau et al., 1995). Several researches indicated that NO generated by human spermatozoa regulates sperm capacitation and associated protein tyrosine phosphorylation that mediated through a cAMP/PKA-dependent pathway (De Lamirande and Gagnon, 1998; Visconti and Kopf, 1998; Thundathil et al., 2003).

In conclusion, under our experimental conditions, treatment of ram spermatozoa with Larginine at a concentration of $0.04 \mathrm{mM}$ for $90 \mathrm{~min}$ was considered the best concentration of L-arginine to be used for in vitro induction of acrosome reaction.

\section{References}

Adnan M. 1970. Effect of arginine on oligospermia Fertil Steril, 21:217-219.

AlL-Ebady AS, Hussain SO, Al-Badry KI, Abd Rajab B. 2012. Effect of adding arginine in different concentrations on some physical properties of poor motile bull sperms during different months. $J$ Vet Med Anim Health, 4:130-135.

Aydin S, Inci O, Alagöl B. 1995. The role of arginine, indomethacin and kallikrein in the treatment of oligoasthenospermia. Int Urol Nephrol, 27:199-202.

Chemineau P, Cognine Y, Guerin Y, Orgeure P, Valtet JC. 1991. Training Manual on Artificial Insemination in Sheep and Goats. Rome, Italy: FAO. 222 pp. FAO Animal Production and HealthPaper, 83.

Darwish GM. 2004. Evaluation of fertilizing efficiency of buffalo spermatozoa in vitro subsequent using some capacitating agents. J Egypt Vet Med Assoc, 64:323336.

De Lamirande E, Gagnon C. 1998. Paradoxical effect of reagents for sulfhydryl and disulfide groups of human sperm capacitation and superoxide production. Free Radic Biol Med, 25:803- 817.

El-Amrawi GA, Nemetallah BR. 1991. Study on capacitation of buffalo spermatozoa. In: 3rd Annual Congress. Egyptian Society for Animal Reproduction and Fertility, 1991, Cairo. Cairo: ESARF. pp. 214-222.

Gagnon C, De Lamirande E. 2006. Control of sperm motility. In: de Jonge C, Barratt C (Ed.). The Sperm cells: Production, Maturation, Fertilization and Regeneration. Cambridge UK: Cambridge University Press. pp. 108-133.

Govil G, Phadke RS, Srivastava S. 1992. Physical/chemical studies of vitamin $\mathrm{E}$ in membranes. In: Ong ASH, Packer L (Ed.). Lipid Soluble Antioxidants: Biochemistry and Clinical Applications.
Basel, Switzerland: BirkhauserVerlag. pp. 27-46

Griveau JF, Dumont E, Renard P, Callegari JP, Le Lannou D. 1995. Reactive oxygen species, lipid peroxidation and enzymatic defense system in human spermatozoa. J Reprod Fertil, 103:17-26.

Harrison RA. 2004. Rapid PKA-catalyzed phosphorylation of boar. Reprod Dev, 67:337-352.

Hassanpour H, Mirshokrai P, Shirazi A, Aminian A. 2007. Effect of nitric oxide on ram sperm motility in vitro. Pak J Biol Sci, 10:2374-2378

Hassanpour H, Teshfam M, Goodarzi AK, Tajik P, Mirshokrai P. 2010. In vitro effects of 1-arginine on motion parameters in ram epididymalsperm. Comp Clin Pathol, 19:351-355.

Herrero MB, Gagnon C. 2001. Nitric oxide: a novel mediator of sperm function. J Androl, 22:349-356.

Jungling ML, Bunge RG. 1976. The treatment of spermatogenic arrest with arginine. Fertil Steril, 27:282283.

Kawakami E, Arai T, Nakamura U. 1999. Effects of medium containing heparin and theophylline on capacitation and metabolic enzyme activities of ejaculated spermatozoa from dogs with asthenozospermia. Anim Reprod Sci, 54:251-259.

Levonen AL, Patel RP, Brookes P, Go YM, Jo H, Parthasarathy S, Anderson PG, Darley-Usmar VM. 2001. Mechanisms of cell signaling by nitric oxide and peroxynitrite: from mitochondria to 354. Comp Clin Pathol, 19:351-355.

Mann T, Lutwak-Mann C. 1981. Biochemistry of seminal plasma and male accessory fluids; application to andrological problems. In: Mann T, Lutwak-Mann C. Male Reproductive Function and Semen. In: Berlin: Springer-Verlag. pp. 269-336.

Marie WF. 2005. The Effect of various capacitating active compounds and capacitation time on the in vitro fertilization of buffalo sperm., Cairo: Faculty of Veterinary Medicine, Cairo University. PhD Thesis.

O'Flaherty C, De Lamirande E. Gagnon C. 2004. Phosphorylation of the arginine- $\mathrm{x}-\mathrm{x}$ (serine/threonine) motif in human sperm proteins during capacitation: modulation and protein kinase A dependency. Mol Hum Reprod, 10:355-363.

Patel AB, Srivastava S, Phadke RS, Govil G. 1998. Arginine activates glycolysis of goat epididymal spermatozoa: an NMR study. Biophys $J$, 75:1522-1528.

Patel AB, Srivastava S, Phadke RS, Govil G. 1999. Arginine acts as a protective and reversal agent against glycolytic inhibitors in spermatozoa. Physiol Chem Phys Med NMR, 31:29-40.

Polakoski KL, Syner FN, Zaneveld LJD. 1976. Biochemistry human seminal plasma. In: Hafez ESE (Ed.). Human Semen and Fertility Regulation in Men. St. Louis: The CV Mosby. pp. 133-143.

Ratnasooriya WD, Dharmasiri MG. 2001. LArginine, the substrate of nitric oxide synthase, inhibits fertility of male rats. Asian J Androl, 3:97-104.

Rodriguez PC, O'Flaherty CM, Beconi MT. Beorlegui NB. 2005. Nitric oxide-induced capacitation of cryopreserved bull spermatozoa and assessment of participating regulatory pathways. Anim Reprod Sci, $85: 231-242$. 
Scibona M, Meschini P, Capparelli S, Pecori C, Rossi P, Menchini FGF. 1994. [L-Arginine and male infertility]. Minerva Urol Nefrol, 46:251-253.

Srivastava S, Desai P, Coutinho E, Govil G. 2006. Mechanism of action of L-arginine on the vitality of spermatozoa is primarily through increased biosynthesis of nitric oxide. Biol Reprod, 74:954-958.

Thundathil J, De Lamirande E, Gagnon C. 2003. Nitric oxide regulates the motility in proteins phosphorylation of the thiamine-glutamine-tyrosine proteins of human spermatozoa during capacitation. Biol Reprod, 68:1291-1298.

Visconti PE, Kopf GS. 1998. Regulation of protein phosphorylation during sperm capacitation. Biol Reprod, 59:1-6.

Younis AI, Zuelke KA, Harper KM, Oliveira A, Brackett BG. 1991. In vitro fertilization of goat oocytes. Biol Reprod, 44:1177-1182. 